\title{
Determination of genetic variations among different Trichoderma isolates using RAPD marker in Bangladesh
}

\author{
M. S. I. Sagar, M. B. Meah' ${ }^{1}$, M. M. Rahman and A. K. Ghose \\ Department of Biotechnology, Bangladesh Agricultural University, Mymensingh-2202, Bangladesh \\ ${ }^{1}$ Department of Plant Pathology, Bangladesh Agricultural University Mymensingh-2202, Bangladesh, \\ Email: sagarbau@yahoo.com
}

\begin{abstract}
Some Trichoderma isolates were collected from different locations of Bangladesh for evaluating their bioefficiency by determining their genetic variations. PCR-based Random Amplified Polymorphic DNA (RAPD) Marker employing 3 decamer primers produced 29 scorable bands of which all $(100 \%)$ were polymorphic. The co-efficient of gene differentiation (Gst) was 1.0000 reflecting the existence of high level of genetic diversity among the isolates. The Unweighted Pair Group Method of Arithmetic Means (UPGMA) dendrogram constructed from Nei's (1972) genetic distance produced 2 main clusters (16 isolates in cluster 1 and 19 isolates in cluster 2). The result indicating their genetic diversity has opened new possibility of using the most efficient and more isolates of Trichoderma in the preparation of effective biopesticide.
\end{abstract}

Keywords: Genetic diversity, Trichoderma, RAPD

\section{Introduction}

Trichoderma is a soil fungi which reproduces asexually which is frequently isolated and most prevalently culturable. It is widely distributed in plant material, decaying vegetation, wood and other diverse habitats (Ranasingh, 2006). Trichoderma spp. are facultative anaerobes, grow saprophytically or as parasites on other Trichoderma and are able to grow in soils having a pH range of $2.5-9.5$, although most of them prefer moderately acidic environment (Grondona, 1997). Most of the Trichoderma strains produce only asexual spores. However, a few strains have sexual stage which are not considered for biocontrol purposes. In recent past, morphological features were considered to determine different taxonomical aspects with the help of the asexual sporulation apparatus, but molecular approaches are now being used.

The strains show a high level of genetic diversity which can be used to produce various products of commercial and ecological interests. They are prolific producers of extra-cellular proteins, and also known to produce enzymes that degrade cellulose and chitin. Many other different strains produce more than 100 different metabolites having antibiotic activities. Since the introduction of biocontrol, Trichoderma species have been recognized as agents for the control of plant diseases and for their roles in increasing plant growth and development. The most useful strains show a property that is known as 'rhizosphere competence' that is, the ability to colonize and grow in association with plant roots. Much of the known biology and many of the uses of these fungi have been documented recently (Harman, 2000). To isolate Trichoderma spp. different media are used. Some selective media are more efficient than others. Depending on the species, Trichoderma can show no growth to broadly spreading growth on Potato Dextrose Agar media and Czapek's agar.

The Random Amplified Polymorphic DNA (RAPD) procedure developed by Williams et al. (1990) and Welsh \& McClelland (1990) involves simultaneous amplification of several anonymous loci in the genome using primers of arbitrary sequence and has been used for genetic, taxonomic and ecological studies of several fungi including Trichoderma (Abbasi et al., 1999; Paavanem-Huhtala et al., 2000). The ability to reliably distinguish members of different species, fingerprint of different genotypes and an estimate of the amount of variation within a species is useful for a breeding program. RAPD is a molecular technique used for such purposes. RAPD technique is easy and inexpensive. The advantages of the RAPDs are, the requirement for small amount of DNA (5-20 ng), single short (9 to $10 \mathrm{bp}$ ) primers of arbitrary sequence, the rapidity to screen for polymorphisms, the efficiency to generate a large number of markers for genomic mapping and the potential automation of the technique. In addition, no prior knowledge of 
sequence is required (Sobral and Honeycutt, 1993). Since primers can be chosen arbitrarily, any organism can be mapped with the same set of primers but there is some loss of information because RAPD markers are dominant rather than co-dominant. If one of the alleles at a RAPD site is unamplifiable, then marker homozygote cannot be distinguished from marker/null heterozygote. Other problems arise if products of different loci have similar molecular weights and so will be indistinguishable on a gel because of comigration. The problem of uncertain homology becomes serious at higher taxonomic levels where it is likely that only a few shared bands are generated. Though RAPD has some limitations, but it is being used as one of the powerful techniques for genetic studies, for example, analysis of genetic variation in plants, fungi and bacteria (Mailer et al., 1994) and construction of the first linkage maps for certain plant species and pathogens (Yang and Quiros, 1995).

IPM Lab biopesticide (code- 34/USDA/BG-ARS122) formulated out of Trichoderma is in commercial use (Meah, 2005). The strain Trichoderma harzianum CP was used in the formulation. A total of 46 isolates were collected from different regions of Bangladesh. Based on growth rate and sporulation capacity, the strain T. harzianum CP was selected and used in the formulation (Meah, 2007). Physiological variations of the isolates were studied earlier but not in details. Variation at molecular level has not been studied. Molecular study may reveal any variation that exists among the isolates in support of the variation in physiological properties. It is well established that previous knowledge about the genetic relationships among breeding materials is crucial for the efficient use of the germplasm in a breeding program (Nienhuis et al., 1994). In Bangladesh, research findings on genetic analysis of different Trichoderma isolates are not available. Although no specific markers were found to discriminate different isolates effectively, the RAPD technique revealed some degree of polymorphisms for variation study of different Trichoderma isolates and the results obtained from the experiment using RAPD markers have been presented and expressed in tables and figures for ease of understanding. More isolates of Trichoderma have been recently collected. The present research work was undertaken to determine genetic variations among some isolates of Trichoderma spp. using RAPD technique for evaluating their efficiency as biopesticides.

\section{Materials and Methods}

An in vitro experiment was conducted at the IPM Laboratory, Department of Plant Pathology and Central Laboratory, Bangladesh Agricultural University, Mymensingh. Part of molecular experiment was conducted at the Biotechnology Laboratory, Bangladesh Institute of Nuclear Agriculture (BINA). Thirty five Trichoderma isolates collected from diverse origin of different hosts and locations in Bangladesh were used in the present experiment. The experiment was designed in a Completely Randomized Design (CRD) with three replications. The activities were performed from November 2009 to June 2010.

\section{Molecular characterization of Trichoderma isolates}

For DNA extraction, mycelial cultures were raised individually in $150 \mathrm{ml}$ conical flasks containing $100 \mathrm{ml}$ potato dextrose broth. Mycelia were collected on filter paper in a Buchner funnel, washed with distilled water, frozen, and lyophilized. After extraction, mycelia were wrapped with aluminium foil for each isolate and kept in refrigerator before genomic DNA isolation. Isolates of Trichoderma spp. were used for the RAPD. The extraction of total genomic DNA of each isolate of Trichoderma was made. As a source of genomic DNA, fresh mycelia samples were collected from the 3 days old culture. Genomic DNA samples of each accession were extracted following phenol: chloroform: isoamyl alcohol extraction and ethanol precipitation method from vigorous and fast actively growing mycelial tissue. DNA was extracted using the mini preparation CTAB method.

\section{Genomic DNA isolation}

Thirty five isolates of Trichoderma spp. were used for the RAPD.Genomic DNA samples of each accession were extracted following phenol: chloroform: isoamyl alcohol extraction and ethanol precipitation method from vigorous and fast actively growing mycelial tissue. Firstly, soft mycelia portion (before spore production in 3 days) of the vigorous and actively growing Trichoderma spp. were cut apart with sterile scissors and forceps. Then ethanol was used to wash scissors and forceps to avoid contamination. The DNA from mycelial tissues was then extracted. 


\section{Confirmation of DNA preparation}

Usually isolated genomic DNA following above protocol contains a large amount of RNA and pigments, which usually cause spuriously high estimation of DNA concentration on a spectrophotometer. For avoiding RNA contamination, RNAase was used in the TE buffer. Therefore DNA samples were evaluated both quantitatively and qualitatively and for the amount of RNA present using spectrophotometer and 1\% agarose gel electrophoresis, respectively.

\section{Quantification of DNA}

Absorbance reading and DNA concentration varied from (0.005-0.404) $\mu \mathrm{l}$ and (250-20200) $\mu \mathrm{l}$ respectively. It is necessary to optimize the amount DNA used in PCR assay to achieve reproducibility and strong signal.Purity and concentration of genomic DNA was examined by calculating the ratio of optical density using a spectrophotometer.

Using the above absorbance readings, the original concentrations were determined according to the following formula:

DNAConc. $(\mathrm{ng} / \mu \mathrm{l})=$ Absorbance $\times \frac{\text { Volume of distilled water }(\mu \mathrm{l})}{\text { Amount of DNA sample }(\mu \mathrm{l})} \times$ Conversion factor $(0.05) \times 1000$

\section{Preparation of working solution of DNA samples}

Before PCR, DNA concentrations were adjusted to $25 \mathrm{ng} / \mu \mathrm{l}$ using the following formula: $V_{1} \times S_{1}=V_{2} \times S_{2}$. Where, $V_{1}=$ Initial volume of DNA solution $(\mu l), S_{1}=$ Initial DNA concentration $(n g / \mu l) \quad V_{2}=$ Final volume of DNA solution $(\mu \mathrm{l}), \mathrm{S}_{2}=$ Final DNA concentration $(\mathrm{ng} / \mu \mathrm{l}) \cdot \mathrm{V}_{2}=\mathrm{V}_{1} \times \mathrm{S}_{1} / \mathrm{S}_{2}$

\section{PCR conditions}

Conditions for RAPD amplification reactions were maintained essentially following (William et al., 1990) with some modifications. PCR reactions were performed on each DNA sample in a $10 \mu \mathrm{l}$ reaction mix. During the experiment, PCR buffer, dNTPs, and primer solutions were thawed from frozen stocks, mixed by vortexing and placed on ice. DNA samples were also thawed out and mixed gently. The primers were pipetted first into PCR tubes compatible with the thermocycler used $(0.2 \mathrm{ml})$. For each DNA sample being tested, a pre-mix was then prepared including in the following order: buffer, dNTPs, DNA template and sterile distilled water. Taq polymerase enzyme was then added to the pre-mix. The pre-mix was then mixed well and aliquoted into the tubes containing primers. The tubes were then sealed and placed in a thermocycler and the cycling was started immediately.

\section{Banding analyses}

Since RAPD markers are dominant, we assumed that each band represented the phenotype at a single allelic locus (Williams et al., 1990). One molecular weight marker, 20 base pair DNA ladder was used to estimate the size of the amplification products by comparing the distance traveled by each fragment with that of the known sized fragments of molecular weight markers. All distinct bands or fragments (RAPD markers) were thereby given identical numbers according to their position on gel and scored visually on the basis of their presence (I) or absence (0), separately for each individual and each primer. Bands which were not identified considered as non-scorable.

\section{Dendrogram construction}

The scores obtained using all primers in the RAPD analysis were pooled to create -a single data matrix. This was used to estimate polymorphic loci, (Nei's, 1972) gene diversity, population differentiation $\left(\mathrm{G}_{\mathrm{st}}\right)$, gene flow (Nm), genetic distance (D) and to construct a UPGMA (Unweighted Pair Group Method of Arithmetic Means) dendrogram among populations using a computer program, POPGENE (Version I .31).The same program was also used to perform test of homogeneity in different loci between population pairs. Gene frequency estimation for RAPD loci was based on the assumption of a two-allele system. Only one of the two alleles is capable to amplify a RAPD marker by primer annealing, at an unknown genomic position (locus). The other is the "null" allele incapable of amplification, mainly because of loss of primerannealing site by mutation. The two-allele assumption is in most cases acceptable because, co-dominant 
loci showing band shifts are few. In this system only a null homozygote is detectable as negative for the RAPD - band of interest. Under the assumption of Hardy-Weinberg equilibrium, the null allele frequency (q) may be $(N / n)^{1 / 2}$, where $N$ and $n$ are the number of band negative individuals observed and the sample size, respectively. The frequency of the other allele $(P)$ is $1-q$. The assumption of the two-allele system enables us to calculate the Nei's, genetic distance (Nei, 1972) from the RAPD pattern. Nei's genetic distance and identity values were computed from frequencies of polymorphic markers to estimate genetic relationship between the studied thirty five Trichoderma isolates using the unweighted pair-group method of arithmetic means (UPGMA). The dendrogram was then constructed using the POPGENE (Version 1.31) computer program.

\section{Results and Discussion}

The stated experiment was undertaken to determine genetic variation among some isolates of Trichoderma spp. using RAPD analysis. The results are presented here.

\section{RAPD Analyses}

Primer selection and RAPD pattern: Six primers were initially screened for their ability to produce polymorphic patterns among 35 isolates of Trichoderma spp. and three primers viz., OPB-09, OPB-10, and OPC-01 which showed comparatively maximum number of high resolution bands and distinct polymorphic amplified products were selected. Selected three primers generated 29 bands all were polymorphic, i.e. there were no monomorphic bands. The three different primers generated various banding patterns, ranging from 12 (OPB-9), 8 (OPB-10) to 9 (OPC-01). The primer OPB-9 and OPC-01 produced the highest numbers of polymorphic bands (12 and 9). Thus it showed a higher level of polymorphism. On the other hand, the primer OPB10 generated least number of polymorphic bands (8). (Table 1).

Table 1. RAPD primers with corresponding bands score and their size range together with polymorphic bands observed in $\mathbf{3 5}$ isolates

\begin{tabular}{|c|c|c|c|c|c|}
\hline $\begin{array}{c}\text { Primer } \\
\text { code }\end{array}$ & $\begin{array}{c}\text { Sequences } \\
\left(5^{\prime}-3^{\prime}\right)\end{array}$ & $\begin{array}{c}\text { Total number } \\
\text { of bands } \\
\text { scored }\end{array}$ & $\begin{array}{c}\text { GC } \\
\text { content }\end{array}$ & $\begin{array}{c}\text { Number of } \\
\text { polymorphic } \\
\text { bands }\end{array}$ & $\begin{array}{c}\text { Proportion of } \\
\text { polymorphic loci (\%) }\end{array}$ \\
\hline OPB-09 & TGGGGGACC & 12 & 70 & 12 & 100 \\
\hline OPB-10 & CTGCTGGGC & 8 & 70 & 8 & 100 \\
\hline OPC-01 & TTCGAGCCG & 9 & 60 & 9 & 100 \\
\hline Total & & 29 & & 29 & 300 \\
\hline Average & & 9.67 & & 9.67 & 100 \\
\hline
\end{tabular}

In the present study the average percentage of polymorphic loci across primers was 100\%. The banding patterns of different Trichoderma isolates using primers OPB-9, OPB-10, and OPC-1 are shown in Plate-1

\section{Grouping of different Trichoderma isolates based on similar bands produced by three primers to determine polymorphism}

In case of primer OPB-09 total number of bands were 12 and some isolates produced similar bands against it, such as $T(22,23), T(25,33)$ and $T(31,42)$. The isolates were rearranged by keeping only one lane from two similar lanes and another lane was discarded. In this way the highest polymorphic loci were found for the primer OPB-09 and the isolates number were reduced from 35 to 32 (Plate 2).Similarly for the primers OPB-10 and OPC-01 the polymorphic loci of the isolates were detected by reducing one lane from two similar lane and the isolates were reduced from 35 to 31 (Plate 3, Plate 4). It can be concluded that, among the three primers OPB-09 produced maximum polymorphism (32 polymorphic bands out of 35) as compared to OPB-10 and OPC-01 (31 from 35). So OPB-09 was the better primer for its capacity to produce the highest polymorphic bands. The DNA polymorphisms were detected according to presence or absence of bands. Absence of bands may be caused by failure of primers to anneal a site in some individuals due to nucleotide sequence differences or by insertions or deletions between primer sites (Clark and Lanigan, 1993) as shown in the Table 2. 


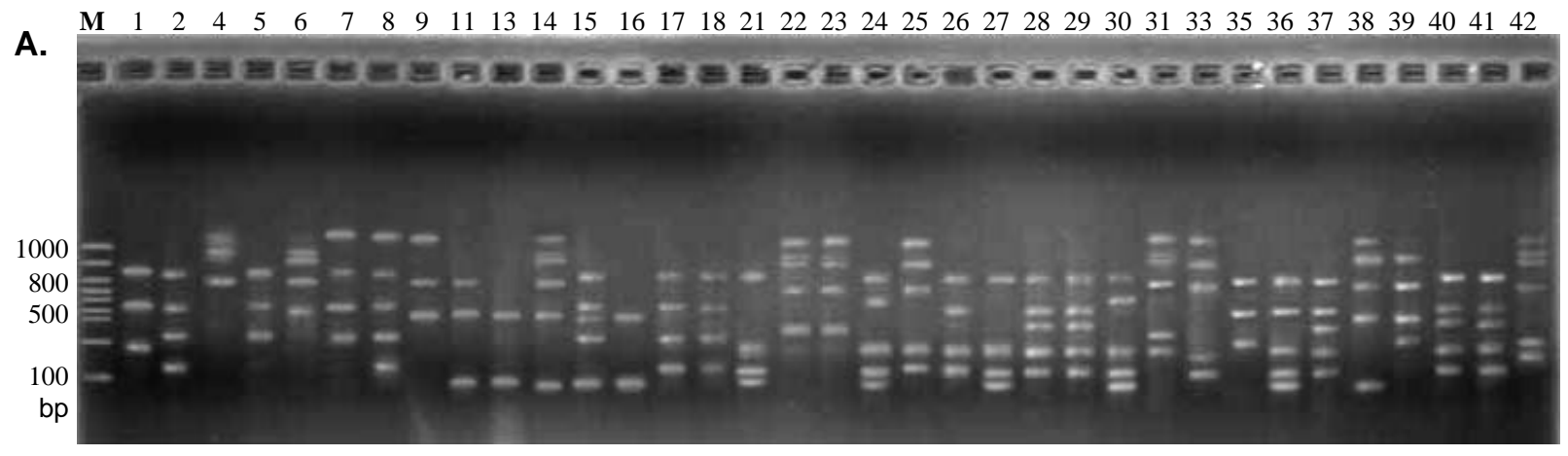

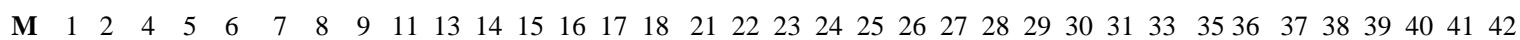
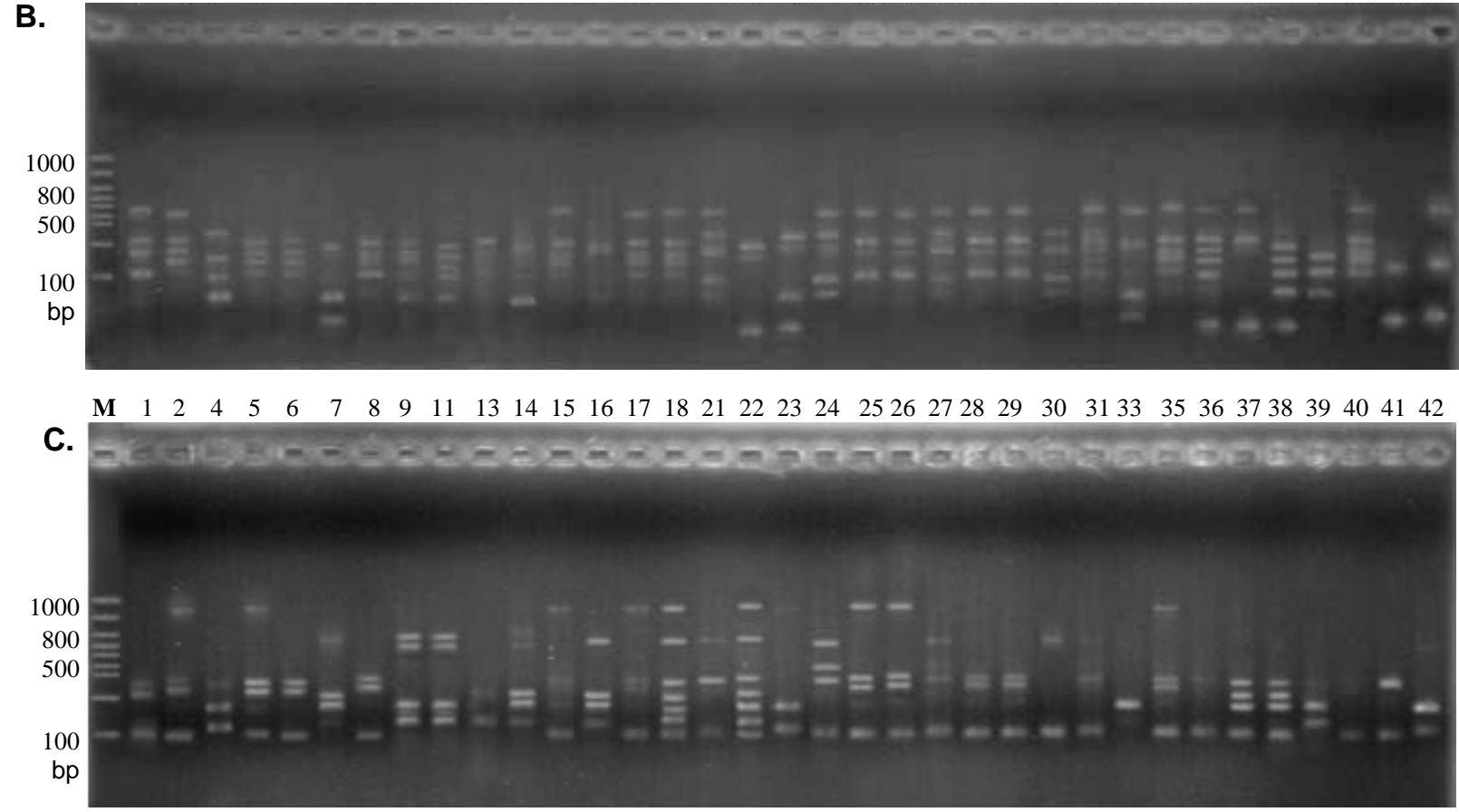

Plate 1. RAPD profiles of different isolates of Trichoderma spp. using primers OPB-9, OPB-10, OPC-01 for bands A, $B, C$, respectively. (Lane M: 20 bp ladder, Lane 1-2: T1 to T2, Lane 4-9: T4 to T9, Lane 11: T11, Lane 13-18 :T13 to T18, Lane 21-31: T21 to T31, Lane 33: T33, Lane 35-42: T35 to T42 on agarose gel)

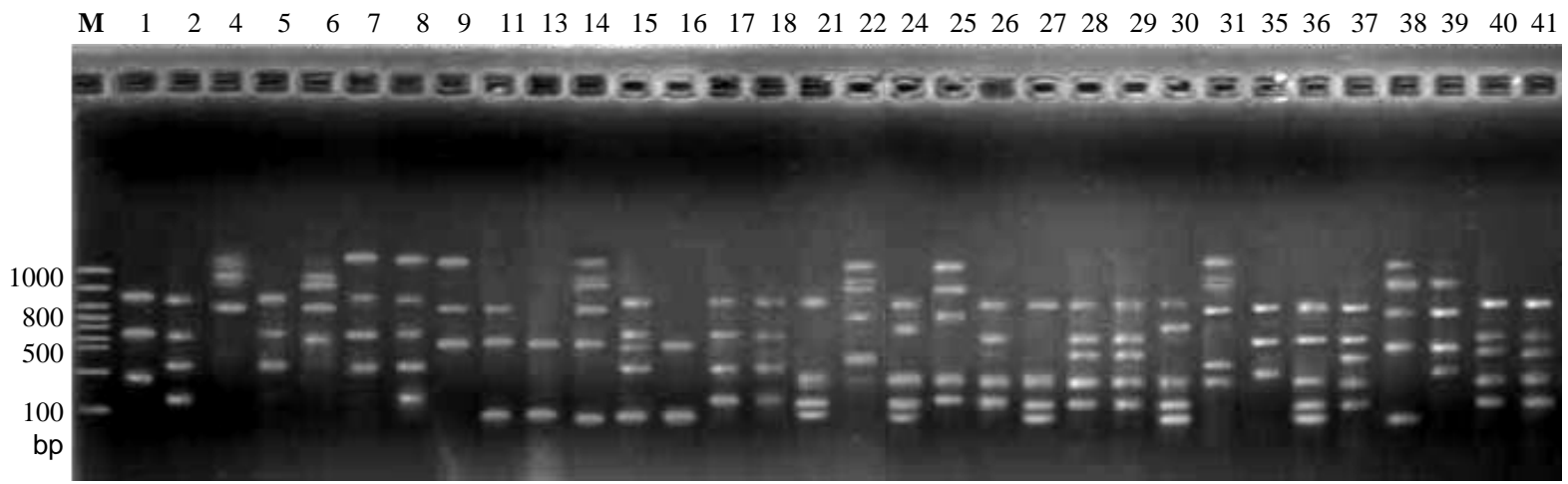

Plate 2. RAPD profiles of different isolates of Trichoderma spp. using primer OPB-9 (Lane M: 20 bp ladder, Lane 12: T1 to T2, Lane 4-9: T4 to T9, Lane 11: T11, Lane 13-18: T13 to T18, Lane 21-22: T21-T22, Lane 24-31: T24-T31, Lane 35-41: T35-T41 on agarose gel) 


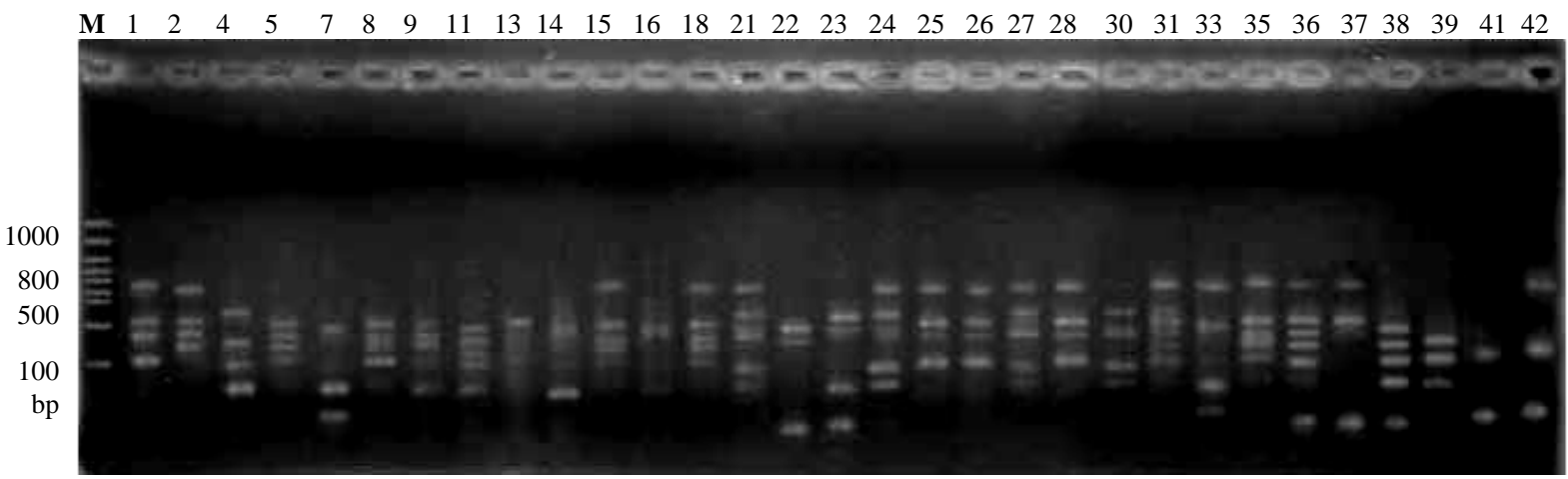

Plate 3. RAPD profiles of different isolates of Trichoderma spp.using primerOPB-10(Lane M: 20bp ladder, Lane 1-2: T1-T2, Lane 4-5: T4-T5, Lane 7-9: T7-T9, Lane 11: T11, Lane 13-16: T13-16, Lane 18: T18, Lane 21-28: T21-T28, Lane 30-31: T30 - $\mathrm{T}_{31}$, Lane 33: T33, Lane 35-39: T35 toT39, Lane 41-42: $\mathrm{T}_{41}-\mathrm{T}_{42}$ on agarose gel

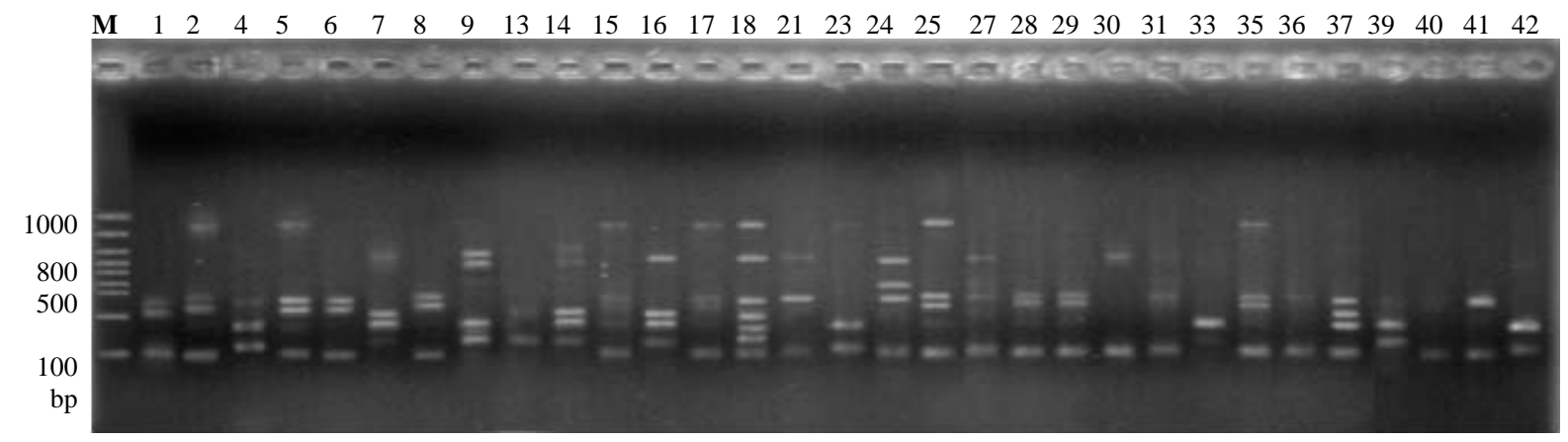

Plate 4. RAPD profiles of different isolates of Trichoderma spp. using primer OPC-1 (Lane M:20 bp ladder, Lane 1-2: T1-T2, Lane 3-4: T4-T5, Lane 5-7: T7-T9, Lane 8-12:T13-T17, Lane 13-17: T21-T25, Lane 18-22: T27-T31, Lane 23: T33, Lane 24-31: T35 to T42 on agarose gel)

Table 2. Frequencies of polymorphic RAPD markers in 35 Isolates of Trichoderma spp

\begin{tabular}{|l|c|c|c|}
\hline RAPD Markers & Gene frequency & RAPD Markers & Gene frequency \\
\hline OPB09-1 & 0.3429 & OPB10-4 & 0.5143 \\
\hline OPB09-2 & 0.2286 & OPB10-5 & 0.4571 \\
\hline OPB09-3 & 0.2857 & OPB10-6 & 0.6286 \\
\hline OPB09-4 & 0.5714 & OPB10-7 & 0.4000 \\
\hline OPB09-5 & 0.3714 & OPB10-8 & 0.2286 \\
\hline OPB09-6 & 0.0857 & OPC01-1 & 0.2857 \\
\hline OPB09-7 & 0.4857 & OPC01-2 & 0.1143 \\
\hline OPB09-8 & 0.3429 & OPC01-3 & 0.3143 \\
\hline OPB09-9 & 0.3429 & OPC01-4 & 0.0571 \\
\hline OPB09-10 & 0.4571 & OPC01-5 & 0.6571 \\
\hline OPB09-11 & 0.4286 & OPC01-6 & 0.4571 \\
\hline OPB09-12 & 0.3143 & OPC01-7 & 0.4000 \\
\hline OPB10-1 & 0.5143 & OPC01-8 & 0.3143 \\
\hline OPB10-2 & 0.1714 & OPC01-9 & 0.7429 \\
\hline OPB10-3 & 0.7429 & & \\
\hline
\end{tabular}




\section{Gene flow and population differentiation}

The average estimated gene flow ( $\mathrm{Nm}$ ) was 0.0000 and co-efficient of gene differentiation (GST) was 1.0000 across all loci (Table 3). Hardy-Weinberg expectation of average heterozygosity in subpopulation $\left(\mathrm{H}_{\mathrm{t}}\right)$ was 0.4136 whereas obtained heterozygosity $\left(\mathrm{H}_{\mathrm{S}}\right)$ was 0.0000 across all primers. RAPD marker revealed high level of differentiation $(G S T=1.0000)$ that supports the presence of sufficient polymorphisms in 35 Trichoderma isolates.

Table 3. Gene flow (Nm) and the proportion of co-efficient of gene differentiation (GST) across different RAPD markers of studied Trichoderma isolates

\begin{tabular}{|c|c|c|c|c|c|}
\hline Locus & Sample Size & Ht & Hs & Gst & Nm $^{*}$ \\
\hline B09-1 & 35 & 0.4506 & 0.0000 & 1.0000 & 0.0000 \\
\hline B09-2 & 35 & 0.3527 & 0.0000 & 1.0000 & 0.0000 \\
\hline B09-3 & 35 & 0.4082 & 0.0000 & 1.0000 & 0.0000 \\
\hline B09-4 & 35 & 0.4898 & 0.0000 & 1.0000 & 0.0000 \\
\hline B09-5 & 35 & 0.4669 & 0.0000 & 1.0000 & 0.0000 \\
\hline B09-6 & 35 & 0.1567 & 0.0000 & 1.0000 & 0.0000 \\
\hline B09-7 & 35 & 0.4996 & 0.0000 & 1.0000 & 0.0000 \\
\hline B09-8 & 35 & 0.4506 & 0.0000 & 1.0000 & 0.0000 \\
\hline B09-9 & 35 & 0.4506 & 0.0000 & 1.0000 & 0.0000 \\
\hline B09-10 & 35 & 0.4963 & 0.0000 & 1.0000 & 0.0000 \\
\hline B09-11 & 35 & 0.4898 & 0.0000 & 1.0000 & 0.0000 \\
\hline B09-12 & 35 & 0.4310 & 0.0000 & 1.0000 & 0.0000 \\
\hline B10-1 & 35 & 0.4996 & 0.0000 & 1.0000 & 0.0000 \\
\hline B10-2 & 35 & 0.2841 & 0.0000 & 1.0000 & 0.0000 \\
\hline B10-3 & 35 & 0.3820 & 0.0000 & 1.0000 & 0.0000 \\
\hline B10-4 & 35 & 0.4996 & 0.0000 & 1.0000 & 0.0000 \\
\hline B10-5 & 35 & 0.4963 & 0.0000 & 1.0000 & 0.0000 \\
\hline B10-6 & 35 & 0.4669 & 0.0000 & 1.0000 & 0.0000 \\
\hline B10-7 & 35 & 0.4800 & 0.0000 & 1.0000 & 0.0000 \\
\hline B10-8 & 35 & 0.3527 & 0.0000 & 1.0000 & 0.0000 \\
\hline C01-1 & 35 & 0.4082 & 0.0000 & 1.0000 & 0.0000 \\
\hline C01-2 & 35 & 0.2024 & 0.0000 & 1.0000 & 0.0000 \\
\hline C01-3 & 35 & 0.4310 & 0.0000 & 1.0000 & 0.0000 \\
\hline C01-4 & 35 & 0.1078 & 0.0000 & 1.0000 & 0.0000 \\
\hline C01-5 & 35 & 0.4506 & 0.0000 & 1.0000 & 0.0000 \\
\hline C01-6 & 35 & 0.4963 & 0.0000 & 1.0000 & 0.0000 \\
\hline C01-7 & 35 & 0.4800 & 0.0000 & 1.0000 & 0.0000 \\
\hline C01-8 & 35 & 0.4310 & 0.0000 & 1.0000 & 0.0000 \\
\hline C01-9 & 35 & 0.3820 & 0.0000 & 1.0000 & 0.0000 \\
\hline Mean & 35 & 0.4136 & 0.0000 & & \\
\hline St. Dev & & 0.0109 & 0.0000 & & \\
\hline & & & & & \\
\hline
\end{tabular}

$\mathrm{N}_{\mathrm{m}}$ = estimate of gene flow from $\mathrm{G}_{\mathrm{ST}}, \mathrm{N}_{\mathrm{m}}=0.5\left(1-\mathrm{G}_{\mathrm{ST}}\right) / \mathrm{G}_{\mathrm{ST}}$

Gst $=$ Co-efficient of gene differentiation

$\mathrm{Ht}=\mathrm{Hardy}-$ Weinberg expectation of average heterozygosity in subpopulations

$\mathrm{Hs}=\mathrm{Hardy}-$ Weinberg expectation of average heterozygosity obtained

The number of polymorphic loci is : 29

The percentage of polymorphic loci is : 100.00

\section{Gene diversity for the RAPD Primer}

Genetic diversity values across all Trichoderma isolates for 3 primers are given in Table 4. Average gene diversity (h) and Shannon's Information index (I) for three primers across different isolates for all loci were found 0.4136 and 0.5984 , respectively. High level of gene diversity value and Shannon's Information index was found in locus OPB09-7, OPB10-1, OPC01-6, (0.4996, 0.4996, and 0.4963, respectively). Lowest level of gene diversity value and Shannon's Information index $(0.1567,0.2841$ and 0.1078$)$ was found in locus OPB09-6, OPB10-2, OPC01-4. 
Table 4. Genetic diversity for three primers in thirty five Trichoderma species

\begin{tabular}{|c|c|c|c|c|c|}
\hline Locus & Sample Size & na* & $n e^{*}$ & $\mathbf{h}^{*}$ & $I^{*}$ \\
\hline B09-1 & 35 & 2.0000 & 1.8202 & 0.4506 & 0.6429 \\
\hline B09-2 & 35 & 2.0000 & 1.5448 & 0.3527 & 0.5375 \\
\hline B09-3 & 35 & 2.0000 & 1.6897 & 0.4082 & 0.5983 \\
\hline B09-4 & 35 & 2.0000 & 1.9600 & 0.4898 & 0.6829 \\
\hline B09-5 & 35 & 2.0000 & 1.8760 & 0.4669 & 0.6597 \\
\hline B09-6 & 35 & 2.0000 & 1.1859 & 0.1567 & 0.2925 \\
\hline B09-7 & 35 & 2.0000 & 1.9984 & 0.4996 & 0.6927 \\
\hline B09-8 & 35 & 2.0000 & 1.8202 & 0.4506 & 0.6429 \\
\hline B09-9 & 35 & 2.0000 & 1.8202 & 0.4506 & 0.6429 \\
\hline B09-10 & 35 & 2.0000 & 1.9854 & 0.4963 & 0.6895 \\
\hline B09-11 & 35 & 2.0000 & 1.9600 & 0.4898 & 0.6829 \\
\hline B09-12 & 35 & 2.0000 & 1.7575 & 0.4310 & 0.6225 \\
\hline B10-1 & 35 & 2.0000 & 1.9984 & 0.4996 & 0.6927 \\
\hline B10-2 & 35 & 2.0000 & 1.3968 & 0.2841 & 0.4581 \\
\hline B10-3 & 35 & 2.0000 & 1.6182 & 0.3820 & 0.5700 \\
\hline B10-4 & 35 & 2.0000 & 1.9984 & 0.4996 & 0.6927 \\
\hline B10-5 & 35 & 2.0000 & 1.9854 & 0.4963 & 0.6895 \\
\hline B10-6 & 35 & 2.0000 & 1.8760 & 0.4669 & 0.6597 \\
\hline B10-7 & 35 & 2.0000 & 1.9231 & 0.4800 & 0.6730 \\
\hline B10-8 & 35 & 2.0000 & 1.5448 & 0.3527 & 0.5375 \\
\hline C01-1 & 35 & 2.0000 & 1.6897 & 0.4082 & 0.5983 \\
\hline C01-2 & 35 & 2.0000 & 1.2538 & 0.2024 & 0.3554 \\
\hline C01-3 & 35 & 2.0000 & 1.7575 & 0.4310 & 0.6225 \\
\hline C01-4 & 35 & 2.0000 & 1.1208 & 0.1078 & 0.2190 \\
\hline C01-5 & 35 & 2.0000 & 1.8202 & 0.4506 & 0.6429 \\
\hline C01-6 & 35 & 2.0000 & 1.9854 & 0.4963 & 0.6895 \\
\hline C01-7 & 35 & 2.0000 & 1.9231 & 0.4800 & 0.6730 \\
\hline C01-8 & 35 & 2.0000 & 1.7575 & 0.4310 & 0.6225 \\
\hline C01-9 & 35 & 2.0000 & 1.6182 & 0.3820 & 0.5700 \\
\hline Mean & 35 & 2.0000 & 1.7478 & 0.4136 & 0.5984 \\
\hline St. Dev & & 0.0000 & 0.2509 & 0.1045 & 0.1224 \\
\hline
\end{tabular}

* na $=$ Observed number of alleles

* ne = Effective number of alleles [Kimura and Crow (1964)]

${ }^{*} \mathrm{~h}=$ Nei's (1973) gene diversity

* I = Shannon's Information index [Lewontin (1972)].

\section{Genetic distance}

The values of pair-wise comparisons of Nei's (1972) genetic distance between 35 Trichoderma isolates were computed from combined data sets for the three primers ranging from 0.0034 to 1.4214.Comparatively higher genetic distance (1.4214) was found between T14 and T $(2,17)$. T14 was dark green, fast growing and very compact isolate, whereas T2 and T17 were whitish green, medium growing and compact isolate. As the isolates T14 and T $(2,17)$ were genetically apart, can be used in breeding programme for improving some desired traits. The lowest genetic distance $(0.0034)$ was revealed between T24 and T27, also in T28 and T29 where all the isolates were fast growing, compact and green and light green in colour. Considering this, it may be concluded that T24, T27, T28 and T29 were originated from same parent or closely related parent. 


\section{Dendrogram}

Dendrogram based on Nei's (1972) genetic distance using Unweighted Pair Group Method of Arithmetic Means (UPGMA) indicated segregation of the 35 isolates of Trichoderma spp. into two main clusters: T4, T6, T7, T9, T11, T13, T14, T16, T22, T23, T25, T31, T33, T38, T39, T42 were grouped into cluster 1, most of which were dark green and yellowish green based on colour and other characters were also similar. On the other hand T1 , T2 , T5 , T8 , T15 , T17 , T18 , T21 , T24 , T26 , T27 , T28 , T29 , T30 , T35, T36 , T37 , T40 , T41 were grouped in cluster 2, most of which were green, light green in colour and all were probably identical based on growth habit, colony consistency etc. (Figure 1). Cluster1 was again divided into two sub-clusters. Sub-cluster 1 has isolate-T $(4,7,9,11,13,14,16,39)$ which are dark green, green, light green, yellow green and isolates $T(6,22,23,25,31,33,38,42)$ belonged to subcluster 2. Sub-cluster 2 was again divided into two sub sub-cluster. Sub sub-cluster 2 were dark green colour. Sub sub-cluster 1 was then divided into two groups. Group1 has isolates green, yellowish green colour and rest was in group 2. Group 2 was divided into two sub groups which were dark green and green. Further, the isolates of cluster 2 were divided into two sub-clusters, sub-cluster 2 contained T21, T24, T27, T30, in which T21, T24, were light green where as T27, T30, were green colour. Rest of the isolates belonged to sub-cluster 1 . After that isolates of sub-cluster 1 were divided into two sub subcluster. Sub sub-cluster 2, all of which were whitish green except T35 which were green colour. Sub subcluster 1 was then divided into two groups. Group 2 contained green colour isolates and Group 1 was divided into two sub-groups, in which sub-group 1 contained light green and dark green whereas subgroup 2 had light green colour isolates. The highest genetic distance (1.4214) was found between T14 and $T(2,17)$ and they remained in different cluster. The genetic distance between $T_{24}, T_{27}$ and $T_{28}, T_{29}$ was lowest (0.0034) and found in a group of the same cluster.

The primers OPB-09 and OPC-01 produced maximum number of bands (12 and 9), whereas OPB10 generated the least number (8). The three primers generated 29 total number of bands and average 10 scorable bands where all were polymorphic bands per primer. Strong and weak bands were produced in the RAPD reactions which is a well known and widely used marker throughout the world. Weak bands resulted from low homology between the primer and the pairing site on the DNA strand (Thormann et al., 1994). In the present study the average percentage of polymorphic loci across primers was 100\%.DNA polymorphism of the Trichoderma isolates were studied in Brazil (Brazilian archives of Biology and technology) by Goes and Costa (2002). In their study a total of 197 bands were produced with the 7 primers OPX12, OPA13, OPX1, OPX2, OPX3, OPX7, OPA-5 and found no monomorphic bands while polymorphic bands were evident. This report strongly supports the current study. Fujimori and Okuda (1993) examined 74 strains of Trichoderma by RAPD profiles and the results were consistent with the morphological, physiological and ecological data of these strains which agree the present study. Schlick et al. (1994) and Zimand et al. (1994) used RAPD markers obtained from arbitrary primers to distinguish strains of Trichoderma. This report agrees the findings of the present investigation.

Molecular characterization of different Trichoderma isolates are not available and there were no specific markers to differentiate the isolates effectively. The RAPD technique revealed some degree of polymorphisms for variation study of thirty five Trichoderma isolates in the present study and the results obtained from the experiment showed significant molecular variation among the isolates in relation to morphological characters. Therefore, findings of the present investigation agree with the report of Kullnig et al. (2000) who recognized about 35 Trichoderma species on the basis of morphological and molecular characters and revealed genetic variability among the isolates through RAPD analysis. Hadrys et al. (1992) have provided relatively simple and inexpensive method for examining variation in the total genome through RAPD-PCR technique. On the other hand Peteira et al. (2001) presented the genetic diversity among Trichoderma isolates by RAPD technique which also supports the results of the present investigation. 


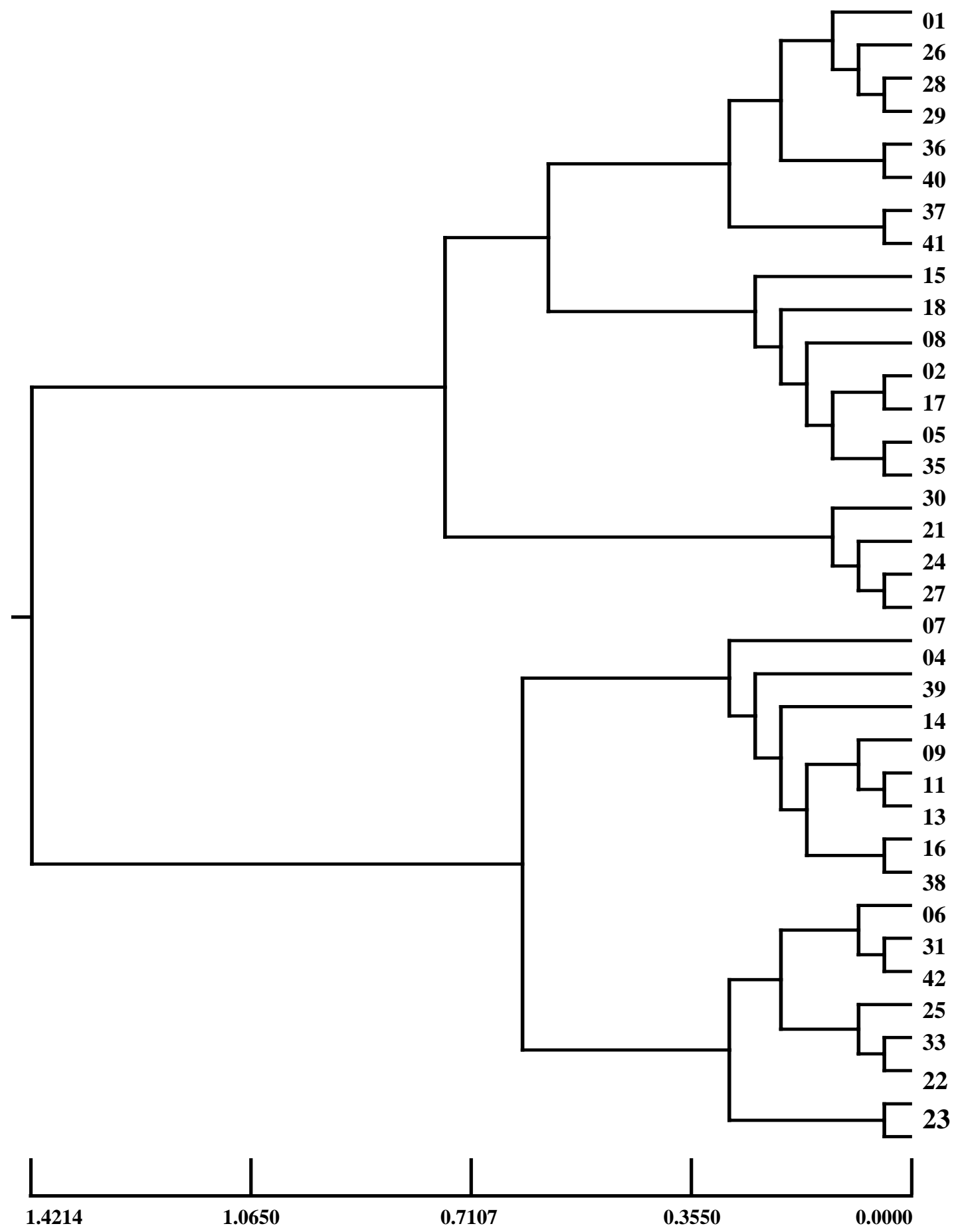

Fig. 1. Unweighted pair group method of arithmetic mean (UPGMA) dendrogram based on Nei's (1972) genetic distance, summarizing data on differentiation in 35 isolates according to RAPD analysis 
Dendrogram based on Nei's (1972) genetic distance using Unweighted Pair Group Method of Arithmetic Means (UPGMA) indicated segregation of the 35 isolates of Trichoderma spp. into two main clusters: T4, T6, T7, T9, T11, T13, T14, T16, T22, T23, T25, T31, T33, T38, T39, T42 were grouped into cluster -1, most of which were dark green and yellowish green in colour. On the other hand T1 , T2 , T5, T8, T15, T17, T18 , T21 , T24 , T26 , T27 , T28 , T29 , T30 , T35 , T36 , T37 , T40 , T41 were grouped in cluster-2, most of which were green, light green and whitish green in colour and probably identical in growth habit, colony consistency which are in agreement with the opinion of Meah (2007) on the study of other research. The highest genetic distance $(1.4214)$ was found between T14 and T $(2,17)$ and they remained in different cluster. The genetic distance between T24, $T_{27}$ and $T_{28}, T_{29}$ was lowest (0.0034) and found in a group of the same cluster. This result indicates that highest genetic diversity remains between the isolates T14 and T $(2,17)$. On the other hand, lowest genetic diversity remains between the isolates T24 and T27, also in T28 and T29.

This study indicates that T14 Vs. T $(2,17)$ and T24 Vs.T27 also T28 Vs. T29 can be used in genetic diversity and more developed analysis for the improvement of beneficial fungi Trichoderma spp. UPGMA dendrogram based on the DICE similarity index (SD) Illustrated the genetic relationships among 14 Trichoderma isolates was described by Goes and Costa (2002) and that partially agree to the present study.

\section{Conclusion}

Highest genetic distance (1.4214) was found between T14 and T $(2,17)$ and they remained in different clusters. The genetic distance between T24 and T27, also in T28 and T29 was the lowest (0.0034) and found in a group of the same cluster. The lowest genetic distance (0.0034) was revealed between T24 and T27, also in T28 and T29. Considering this, it may be concluded that T24, T27, T28 and T29 were originated from same parent or closely related parents.

From the study, it can be concluded that RAPD markers can be sensitive, simple, efficient and powerful tool for genetic diversity analysis among and within Trichoderma isolates and effectively trace their genetic relationships and which could be useful for distinguishing the most efficient isolate for its use in different beneficial purposes.

\section{References}

Abbasi, P.A., Miller, S.A., Meulia, T., Hoitink and Kim, J.M. 1999. Precise detection and tracing of Trichoderma hamatum 382 in compost-amended potting mixes by using molecular markers. Applied Environmental Microbiology. 65(12): 5421-5426.

Clark, A.G. and Langigan, C.M.S. 1993. Prospects for estimating nucleotide divergence with RAPDs. Mol. Evol. 10: 1096-1111.

Fujimori, F. and Okuda, T. 1993. Application of the random amplified polymorphic DNA using the polymerase chain reaction for efficient elimination of duplicate strain in microbial screening. The journal of antibiotics. 47(2): 173-182.

Goes, L.B. and Costa, A.B.L.D. 2002. Randomly amplified polymorphic DNA of Trichoderma isolates and antagonism against Rhizoctonia solani. Braz. arch. biol. technol. Vol.45, No.2.

Grondona, I. and Hermosa, M.1997. Physiological and biochemical characterization of Trichoderma harzianum, a biological control agent against soilborne fungal plant pathogens. Appl. Environ. Microbiol. 63:3189-3198.

Hadrys, H., Balicki, M. and Schierwater, B. 1992. Application of random amplified polymorphic DNA (RAPD) in molecular ecology. Mol Ecol. 1: 55-63.

Harman, G. E. 2000. The myths and dogmas of biocontrol: changes in perceptions derived from research on Trichoderma harzianum strain T-22. Plant Disease. 84:377-393.

Kullnig,C., Szakacs,G., Kubicek, C.P. 2000. Molecular identification of Trichoderma species from Russia, Siberia and the Himalaya. Mycological Research.104(9): 1117-1125.

Mailer, R.J., Scarth, R. and Fristensky, B. 1994. Discrimination among cultivars of rapeseed (Brassica napus L) using DNA polymorphisms amplified from arbitrary primers. Theor Appl Genet. 87: 697-704.

Meah, M.B. and Islam, M.M. 2005. Development of an integrated approach for management of Phomopsis blight and fruit rot of eggplant in Bangladesh. Annual research report (2004-2005). Department of Plant Pathology, Bangladesh Agricultural University, Mymensingh, Bangladesh. p. 42. 
Meah, M.B. 2007. Formulation of Bio-pesticide in controlling Phomopsis fruit rot, foot/collar rot and shoot and fruit borer of eggplant. annual research Report (2006-2007), USDA-Bangladesh Collaborative Research. p.4-11

Nei, M. 1972. Genetic distance between populations .American Naturalist, 106: 283-292.

Nienhuis, J., Tivang, J. and Skroch, P. 1994. Analysis of genetic relationships among genotypes based on molecular markers data. In Analysis of Molecular Marker Data. Corvallis, Oregon. Proceedings. Corvallis, American Soc. Hortic. Sci. Crop. pp.8-14.

Paavanem- Huhtala, S., Avikainem, H. and Ylimattila, T. 2000. Development of strain specific primers for a strain of Gliocladium catenulatum used in biological control. 106(2): 187-198.

Peteira, B., Martinez, B., Muniz, Y., Miranda, I. 2001. Molecular characterization of the genetic diversity of some promising isolates of Trichoderma spp. by RAPD. Revista-de-Proteccion-Vegetal. 16(2/3): 157-158.

Ranasingh, N. 2006. Working in the Regional Centre of Central Tuber Crops Research Institute, Dumduma, Bhubaneswar -751019.

Schlick, A., Kuhls, K. and Messner, K. 1994. Fingerprinting reveals gamma-ray induced mutations in fungal DNA: implications for identification of patent strains of Trichoderma harzianum. Current Genetic. 26. 74-78.

Sobral, B.W.S. and Honeycutt, R.J. 1993. High output genetic mapping in polyploids using PCR generated markers. Theor Appl. Genet. 86: 105-112.

Thormann C.E., Ferreira M.E., Camargo L.E.A., Tivang J.G. and Osborn T.C. 1994. Comparison of RFLP and RAPD markers for estimating genetic relationships within and among cruciferous species. Theor Appl Genet, 88: 973-980.

Welsh, J. and McClelland, M. 1990. Fingerprinting genomes using PCR with arbitrary primers. Nucleic Acids Research. 18: 72137218.

Williams, J.G.K., Kubclik, A.R., Livak, K.J., Rafalski, J.A. and Tingey, S.V. 1990. DNA polymorphisms amplified by arbitrary primers are useful as genetic markers. Nucleic Acids Res. 18: 6531-6535.

Yang, X. and Quiros, C.F. 1995. Construction of a genetic linkage map in celery using DNA based markers, Genome. 38: 36-44.

Zimand, G., Valinsky, L., Elad, Y., Chet, I. and Manulis, S. 1994. Use of the RAPD procedure for the identification of Trichoderma strains. Mycological Research. 98(5): 531-534. 